\title{
The Incidence of Smoking Habits and the Degree of Nicotine Dependence in Education Workers
}

\author{
${ }^{1}$ Medical Faculty, University of Zenica, \\ Bosnia and Herzegovina, ${ }^{2}$ Institute of \\ Public Health, Central Bosnia Canton, \\ Travnik, Bosnia and Herzegovina
}

Sead Karakaš ${ }^{1,2}$, Mateja Paklarčić ${ }^{2}$, Ermina Kukić

\author{
Correspondence: \\ tr.zavod@bih.net.ba \\ Tel.: + 38730511394 \\ Fax.: + 38730511633
}

Received: 5 March 2019

Accepted: 15 August 2019

Key Words: Smoking - Dependence Fagerstrom Test - Education Worker.

\begin{abstract}
Objective. The aim of this research was to establish the incidence of smoking habits and the level of nicotine dependence in education workers in the Central Bosnia Canton (CBC). Materials and Methods. The research was conducted in the 2017/2018 school year. It covered education workers in all elementary $(\mathrm{N}=53)$ and high schools $(\mathrm{N}=23)$, in the area of the CBC. A total of 857 subjects were included. For the purpose of this research a special questionnaire was designed that included information on smoking, how long people had smoked, age and gender, smoking habits, and a modified Fagerstrom test for assessment of nicotine dependence. Results. In relation to smoking status, the subjects were divided into two categories: $646(75.38 \%)$ non-smokers and $211(24.62 \%)$ of those who declared themselves to be active smokers. All subjects were considered in relation to four age groups. The average age of the subjects was 42.14 years, and the average age of the subjects who were smokers was 43.61 years. Of the total number of smokers $(n=211)$, the number of those who believed that the consumption of cigarettes by staff members encourages pupils to smoke was $76(36.01 \%)$. The largest number of subjects $(746,87 \%)$ believed that during their time in school or the school yard, pupils are in a situation where they are able to see educational workers smoking. The degree of nicotine dependence in education workers in the CBC was mostly mild $(53.55 \%, \mathrm{~N}=113)$ and then moderate $(44.54 \%$, $\mathrm{N}=94)$ and severe $(1.89 \%, \mathrm{~N}=4)$. Conclusion. There is a significant number of smokers $(24.62 \%)$ amongst education workers in schools in the CBC. The level of nicotine dependence in education workers is most often mild (53.55\%) then moderate (44.54\%) and severe (1.89\%).
\end{abstract}

\section{Introduction}

Tobacco smoke is produced by the incomplete combustion of tobacco leaves and contains about 7000 chemical compounds, of which the most harmful are tar compounds, carbon monoxide, and nicotine. Nicotine and tobacco products are related to dependence. Some studies have revealed that tobacco products, and especially cigarettes, are related to levels of dependence equivalent to illegal drugs (1).
In today's modern world, tobacco smoking is a pervasive dependence disease, the most widespread social disease and a toppriority public health problem. Non-infectious diseases (primarily carcinomas, diabetes, cardiovascular diseases and chronic lung diseases) are directly responsible for more than 36 million deaths each year. In view of the fact that tobacco is the greatest risk factor for non-infectious diseases, avoiding tobacco is of crucial important in 
reducing premature deaths (2). Tobacco use is still clearly a major public health issue, and it is critically important to identify the risk factors related to starting smoking. Most research dealing with smoking has focused on adolescents, because preventing them starting to smoke is one of the most valuable approaches to reducing the burden of smoking. Moreover, thousands of adolescents try cigarettes every day, and some of them will become adults addicted to smoking (3).

Adolescence is a period of "increased vulnerability" to incitement to use tobacco. Various factors have been identified as initiators of smoking in adolescents. In view of the fact that adolescents spend most of their time in school, teachers can have an important influence, because they interact with pupils almost every day. The use of tobacco by teachers and approval of the use of tobacco amongst this important group of people is likely to increase the probability of smoking by pupils, due to the perception that using tobacco is normative, commonplace and acceptable behaviour (4). This is especially so because teachers are also those responsible for teaching plans and lessons aimed at preventing smoking, and key leaders in creating public opinion relating to school policies on combating tobacco use (5).

Smokers mainly admit the harm they are doing to themselves, and many say they do not enjoy it, but they still smoke. The reason for this is that the nicotine in the cigarettes creates a strong urge to smoke, which undermines and overwhelms concerns about the negative consequences of smoking and the decision not to smoke in those who are trying to stop (6). Dependence on cigarettes stems from the fact that they supply a highly controlled dose of a drug, nicotine, to the brain quickly and in a form which is accessible, available and pleasant (7). At the end of the last century the importance was recognized of nicotine in maintaining the smoking habit, and the difficulties in stop- ping smoking. This led to the need to create an instrument to measure nicotine dependence (8).

The aim of this research was to establish the incidence of smoking habits and the level of nicotine dependence in education workers in the Central Bosnia Canton (CBC).

\section{Materials and Methods}

\section{Area of Research}

The CBC is an administrative unit of the Federation of Bosnia and Herzegovina. It is located in the central part of Bosnia and Herzegovina and has an area of $3,189 \mathrm{~km}^{2}$, with a population in 2015 of 251,714 inhabitants, of whom 58,021 are children aged from $0-18$ years. This research included education workers from eleven municipalities of the CBC (9).

\section{Subjects}

The research took place during the 2017/2018 school year and 873 permanently employed education workers took part from all elementary schools $(\mathrm{N}=53)$ and high schools $(\mathrm{N}=23)$ in the eleven municipalities of $\mathrm{CBC}$.

\section{Methods}

The research was conducted in the form of a questionnaire. It was voluntary and anonymous. Anonymity was ensured whereby the questionnaire was conducted in the schools and the subjects completed the questionnaire themselves and it did not require any personal details. It was placed into a box prepared in advance. For the needs of this research, a specially structured questionnaire was designed with 20 questions, which contained information on smoking, how long they had smoked, their age and gender, smoking habits, and a modified Fagerstrom 
test for assessment of nicotine dependence $(8,10)$. Fagerstrom's test for nicotine dependence was developed in 1978 and tests dependence on nicotine using the self-assessment method. The questionnaire was distributed to the teachers in person, and the professional staff gave oral instructions about how to complete the questionnaire and the purpose of the research, and were available for any questions. The teachers were assured that the information they gave would remain confidential, so they were encouraged to be honest in their answers. The questionnaire had to be fully completed to be included in the analysis.

For assessment of dependence, we analysed the replies that are an integral part of the Fagerström Tolerance Questionnaire. It consisted of 6 questions with answers supplied. Each answer carried $0,1,2$ or 3 points, whereby the total score indicated the nicotine dependence of the individual subject. Scores were from $0-11$ points. Mild nicotine dependence in a smoker produces a score of $0-3$ points, moderate dependence 4- 8 points, and more than 9 points indicates severe dependence.

\section{Ethical Aspects of the Research}

The Ethics Committee of the Institute for Public Health of the CBC approved the research (no. 1-03-06/18). All participants gave verbal consent to participation in this research. The informed consent of the teacher was presumed when they completed and returned the questionnaire.

\section{Statistical Analysis}

Data entry was initiated at the same time as the data were collected. The data in the research were checked, verified and entered into MS Excel 2013. Incomplete and inconsistent data were rejected and not included in the final analysis. In the end, data for 857 subjects were used for analysis. Data analysis was undertaken using SPSS version 17 software. Numerical and percentage distributions were used to present the descriptive data, the hi-square test was used to confirm correlations, and statistical significance was tested at a level of $5 \%$ probability.

\section{Results}

Of the total number of subjects $(\mathrm{N}=857)$ the research included 267 (31.16\%) men and 590 (68.84\%) women. Regarding the percentages of subjects related to place of residence, 544 (63.48\%) subjects were from urban settings, and $313(36.52 \%)$ a rural environment. Of the total number of smokers $(\mathrm{N}=211)$, those from a rural setting had a share of $66 / 313$ (21.09\%), whilst $145 / 544$ (26.65\%) smokers were from an urban environment $\left(\chi^{2}=3.02\right.$ i $\left.\mathrm{P}=0.082\right)$ that is, there was no statistically significant difference in the number of smokers in relation to their place of residence. In relation to gender, the proportion of women smokers was 143/590 (24.2\%) in comparison to men with $68 / 267$ $(25.5 \%)\left(\chi^{2}=0.09(\mathrm{P}=0.763)\right.$. The difference is not statistically significant.

In terms of smoking status, the subjects were divided into two categories: 211 (24.62\%) declared themselves to be active smokers, and 646 (75.38\%) non-smokers (Table 1). The non-smokers also included former smokers, 169 of them (19.72). The difference in distribution of smokers and non-smokers in age groups was statistically significant $\left(\chi^{2}=8.60 ; \mathrm{P}=0.035\right)$.

The largest number of subjects was in the 31 - 40 years age group $(35.12 \%)$. The average age of the subjects was 42.14 years, where smokers were on average older, 43.61 years, and non-smokers 41.66. The largest number of subjects who were smokers had consumed cigarettes for more than 15 years $(42.65 \%)$, followed by the group who had smoked for 5-10 years (28.44\%), and a 
Acta Medica Academica 2019;48(2):193-204

Table 1. Subjects in Relation to Age Group and Smoking Status

\begin{tabular}{llll}
\hline \multirow{2}{*}{ Age (years) } & Subjects & Smokers & Non-smokers \\
\cline { 2 - 4 } & $\mathrm{N}(\%)$ & $\mathrm{N}(\%)$ & $\mathrm{N}(\%)$ \\
\hline $21-30$ & $136(15.87)$ & $22(10.43)$ & $114(17.65)$ \\
\hline $31-40$ & $301(35.12)$ & $77(36.49)$ & $224(34.67)$ \\
\hline $41-50$ & $205(23.92)$ & $48(22.75)$ & $157(24.30)$ \\
\hline $51-65$ & $215(25.09)$ & $64(30.33)$ & $151(23.37)$ \\
\hline Total & $857(100)$ & $211(100)$ & $646(100)$ \\
\hline Mean \pm SD & $42.14 \pm 10.55$ & $43,61 \pm 10,50$ & $41.66 \pm 10.52$ \\
\hline
\end{tabular}

group for 11 - 15 years (18.96\%) whilst the fewest smokers were in the group who had smoked for up to 5 years. The average length of smoking was 14.84 years (Table 2).

In relation to the length of work in education, the largest proportion of subjects, $361(42.12 \%)$, stated that they had worked for more than 15 years, $326(38.04 \%)$ subjects had worked for 5-15 years, and 170 (19.84\%) subjects had worked in education for less than 5 years.

To the question "To what extent are you responsible for improving live style habits in school children?" the largest proportion of subjects $(403,47.02 \%)$ replied that this was not one of their primary tasks, but that they sometimes taught children about health, 352 (41.07\%) subjects replied that this was one of their primary tasks, and that they taught children a great deal about health, whilst 102 (11.91\%) subjects did not teach children at all about topics related to life style habits. Of the $352(41.07 \%)$ subjects who teach children about health a great deal, 130 smoke (29.26\%). A large proportion of subjects $(514,59.98 \%)$ stated that they believe consumption of cigarettes by teaching staff encourages pupils to consume them too, whilst $343(40.02 \%)$ subjects replied negatively. In our sample there was a statistically significant difference in the attitude of subjects about how far teaching staff smoking cigarettes encourages pupils to do the same $\chi^{2}=34.12(\mathrm{P}=0.052)$.

There was also a significant difference in the attitude of smokers in comparison to non-smokers. Of the total number of smokers (211), the number of those who believe that consuming cigarettes by teaching staff encourages pupils to smoke too was $76(36.01 \%)$, whilst the number of smokers who do not believe that consumption of cigarettes by teaching staff encourages pupils to consume them too was 135 (63.98\%); where $\chi^{2}=66.78(\mathrm{P}=0.053)$.

Table 2. Smoker Subjects in Relation to the Duration of Smoking

\begin{tabular}{lllll}
\hline \multirow{2}{*}{ Age group (years) } & \multicolumn{4}{l}{ Length of smoking (years) } \\
\cline { 2 - 5 } & $1-5$ & $6-10$ & $11-15$ & $\geq 15$ \\
\cline { 2 - 5 } & $\mathrm{N}(\%)$ & $\mathrm{N}(\%)$ & $\mathrm{N}(\%)$ & $\mathrm{N}(\%)$ \\
\hline$<30$ & $9(42.7)$ & $11(18.3)$ & $2(5.0)$ & - \\
\hline $31-40$ & $9(42.9)$ & $33(55.30)$ & $20(50.0)$ & $15(16.7)$ \\
\hline $41-50$ & $3(14.3)$ & $6(10.30)$ & $13(32.5)$ & $26(28.9)$ \\
\hline$>50$ & - & $10(16.7)$ & $5(12.5)$ & $49(54.4)$ \\
\hline Total & $21(100)$ & $60(100)$ & $40(100)$ & $90(100)$ \\
\hline \multicolumn{7}{l}{ Mean $\pm S D$} & $14.84 \pm 7.50$ years. & \\
\hline
\end{tabular}




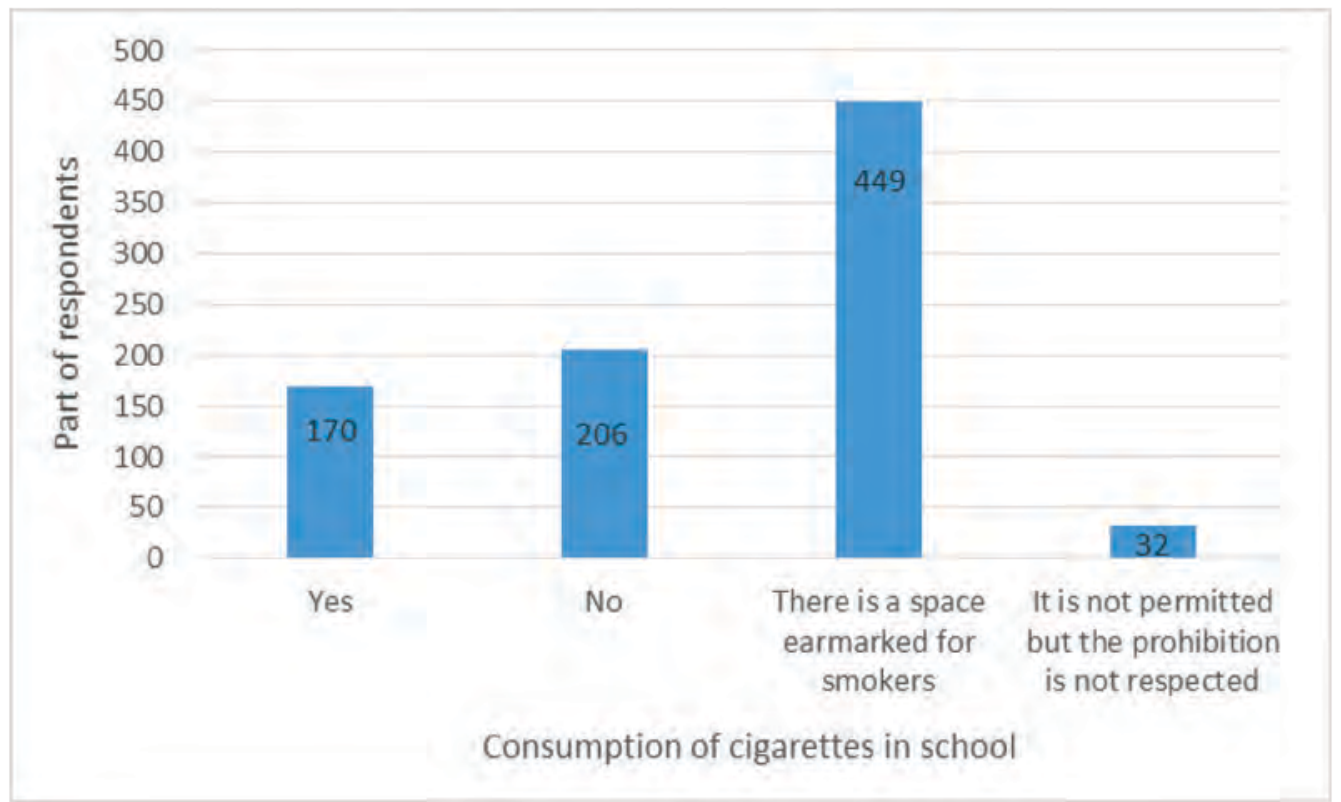

Figure 1. Consumption of Cigarettes by Education Workers During Their Time in School.

To the question "Do you consume cigarettes during working hours?" most of the subjects $(136,64.45 \%)$ stated that they consume cigarettes during their working hours, whilst 75 (35.55\%) do not consume cigarettes during their working hours. The largest number of subjects, 746 (87\%), believed that during their time in school or the school yard, pupils are in a situation where they see educational workers smoking. Most subjects stated that a special place was provided in the school for smokers (449), whilst 170 subjects stated that it was permitted to smoke cigarettes in the work place without any form of restrictions (Figure 1).

To the question "Are you acquainted with the negative consequences of consuming cigarettes?" most of the subjects (759, $88.56 \%)$ replied that they were fully aware, 85 (9.92\%) were superficially acquainted, and $13(1.52 \%)$ were not acquainted with the negative consequences of consuming cigarettes and they did not care.
Of the total number of subjects who declared themselves to be smokers, the largest share, $82(38.86 \%)$ of them, had not tried to stop smoking and were not thinking about it, $55(26.07 \%)$ of them had tried and reduced their consumption, 53 (25.12\%) subjects had tried to stop smoking but had not succeeded, whilst the smallest number of subjects, 21 (9.95\%), had tried to stop smoking and had succeeded temporarily. For each subject, a dependence score was calculated, and the total results obtained by analysis of the Fagerstrom test are shown in Table 3.

On the basis of the results obtained, the level of nicotine dependence of education workers in CBC was calculated. In the 211 subjects who declared themselves to be smokers, nicotine dependence was mostly mild, $53.55 \%(\mathrm{n}=113)$, then moderate, $44.54 \%$ $(\mathrm{n}=94)$, and severe in $1.89 \%(\mathrm{n}=4)$ (Figure 2).

Men mostly showed a moderate level of nicotine dependence (57.35\%), whilst women most often show mild nicotine dependence $(60.83 \%)$ (Table 4$)$. 
Table 3. Results of the Fagerstrom Test

\begin{tabular}{|c|c|c|c|c|c|c|}
\hline \multirow{2}{*}{ Nicotine dependence } & \multicolumn{2}{|c|}{ Male } & \multicolumn{2}{|c|}{ Female } & \multicolumn{2}{|c|}{ Total } \\
\hline & $\mathrm{N}$ & $\%$ & $\mathrm{~N}$ & $\%$ & $\mathrm{~N}$ & $\%$ \\
\hline \multicolumn{7}{|c|}{ 1. How soon after you wake up do you smoke your first cigarette? } \\
\hline a. Less than 5 minutes & 3 & 4.41 & 9 & 6.29 & 12 & 5.68 \\
\hline b. 5-30 minutes & 43 & 63.23 & 57 & 39.86 & 100 & 47.38 \\
\hline c. $30-60$ minutes & 22 & 32.35 & 77 & 53.84 & 99 & 46.91 \\
\hline \multicolumn{7}{|c|}{$\begin{array}{l}\text { 2. Do you find it difficult to refrain from smoking in places where it is forbidden (e.g., at the library, in the theatre, the } \\
\text { doctor's)? }\end{array}$} \\
\hline a. Yes & 15 & 22.05 & 19 & 13.28 & 34 & 16.10 \\
\hline b. No & 53 & 77.94 & 124 & 86.71 & 177 & 83.87 \\
\hline \multicolumn{7}{|c|}{ 3. Which cigarette would you hate most to give up? } \\
\hline $\begin{array}{l}\text { a. The first in the morning, } \\
\text { after you wake up }\end{array}$ & 31 & 45.58 & 61 & 42.65 & 92 & 43.59 \\
\hline b. Any other during the day & 37 & 54.41 & 82 & 57.34 & 119 & 56.39 \\
\hline \multicolumn{7}{|c|}{ 4. How many cigarettes per day do you smoke? } \\
\hline a. $<10$ cigarettes & 10 & 14.70 & 71 & 49.65 & 81 & 38.37 \\
\hline b. 11-20 cigarettes & 38 & 55.88 & 64 & 44.75 & 102 & 48.33 \\
\hline c. $21-30$ cigarettes & 19 & 27.94 & 6 & 4.19 & 25 & 11.84 \\
\hline d. $\geq 31$ cigarettes & 1 & 1.47 & 2 & 1.39 & 3 & 1.41 \\
\hline \multicolumn{7}{|c|}{ 5. Do you smoke more frequently during the first hours after waking than during the rest of the day? } \\
\hline a. Yes & 27 & 39.70 & 29 & 20.27 & 56 & 26.54 \\
\hline b. No & 41 & 60.30 & 114 & 79.72 & 155 & 73.45 \\
\hline \multicolumn{7}{|c|}{ 6. Do you smoke when you are so ill that you are in bed most of the day? } \\
\hline a. Yes & 19 & 27.94 & 28 & 19.58 & 47 & 22.27 \\
\hline b. No & 49 & 72.05 & 115 & 80.42 & 164 & 77.72 \\
\hline
\end{tabular}

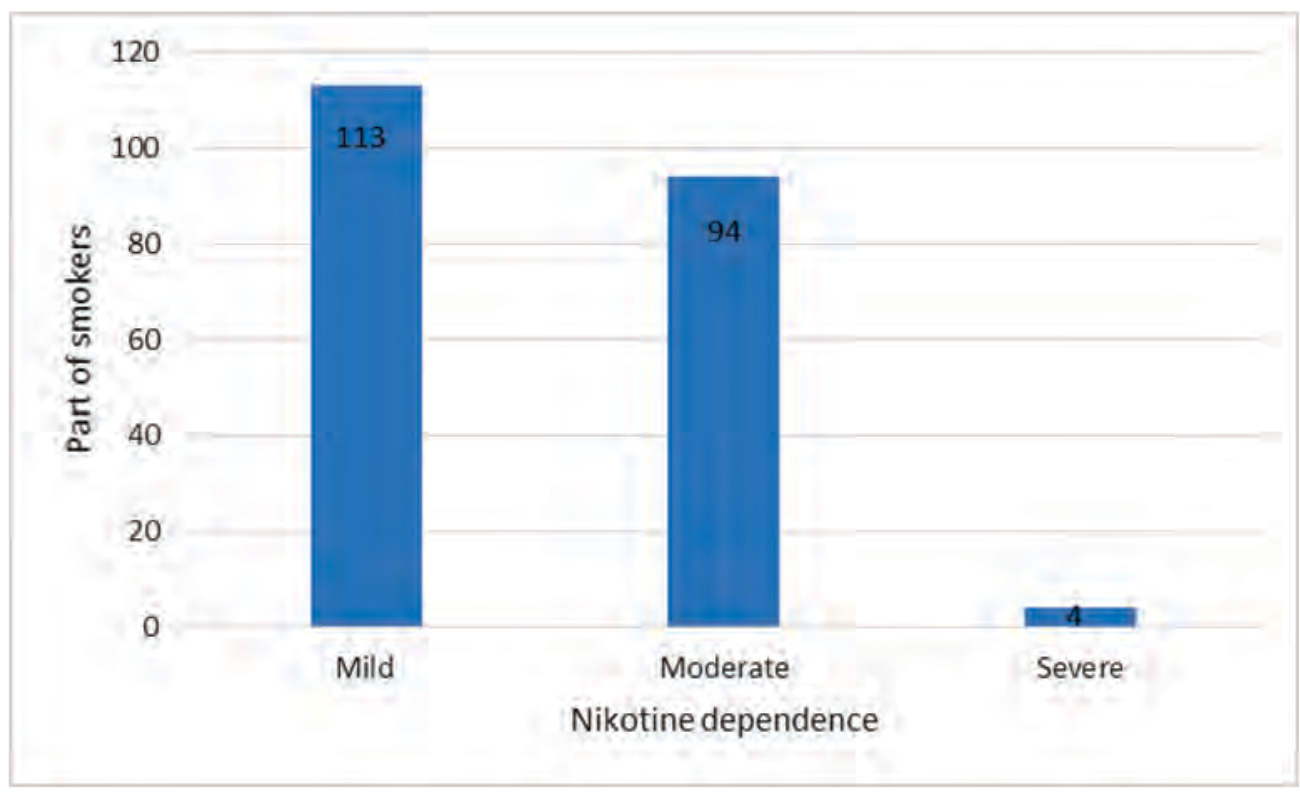

Figure 2. The Level of Nicotine Dependence of Education Workers in the Central Bosnia Canton. 
Table 3. Results of the Fagerstrom Test

\begin{tabular}{llll}
\hline \multirow{2}{*}{ Level of nicotine dependence } & Total & $\mathrm{M}$ & $\mathrm{F}$ \\
\cline { 2 - 4 } & $\mathrm{N}(\%)$ & $\mathrm{N}(\%)$ & $\mathrm{N}(\%)$ \\
\hline Mild nicotine dependence & $113(53.55)$ & $26(38.23)$ & $87(60.83)$ \\
Moderate nicotine dependence & $94(44.54)$ & $39(57.35)$ & $55(38.46)$ \\
Severe nicotine dependence & $4(1.89)$ & $3(4.41)$ & $1(0.70)$ \\
\hline
\end{tabular}

\section{Discussion}

Our research showed that every fourth teacher in schools in CBC smokes. These findings also indicate that there is no statistically significant difference in smokers in relation to gender, nor in relation to place of residence (urban/rural). The largest number of smokers had consumed cigarettes for longer than 15 years. In addition, about $30 \%$ of teachers who are involved in the teaching process with the task of teaching children about improving their life style habits, also smoke. This shows that there is a significant number of smokers amongst teaching staff, and also that smoking habits are very prominent. Although a statistically significant difference was expected between the subjects who smoke in relation to gender and place of residence, it was not found. This expectation was based on most research which indicates that of the almost $20 \%$ of the world's population who smoke, men are represented more in a ratio of 4:1 (about 800 million men and 200 million women) (11). However, mortality from smoking indicates a different relationship. Every year 6 million active smokers die from smoking and also 600,000 passive smokers, $75 \%$ of which are women and children (12-14).

On the other hand, our study showed that in the subject population there is a statistically significant difference in their attitude about how far smoking cigarettes by teaching staff encourages pupils to smoke as well. Smokers take the attitude that their consumption of cigarettes does not encourage pupils to smoke as well, but this atti- tude is significantly different in smokers in comparison to non-smokers. Otherwise, smoking by teachers, parents and friends is described as an important predictor of adolescents' decisions to smoke or not $(15,16)$. Poulsen et al. discovered that teachers who smoke outside are a significant predictor of smoking by pupils (17).

Some authors did not express any correlation between teaching staff smoking and actual smoking by pupils (18). Others found evidence of a positive link between teachers who smoke in the school yard and smoking by older pupils, but also younger pupils (19). Several mechanisms may explain this connection between smoking by teachers and smoking by pupils. According to the Social Ecological Model and the Social Learning Theory, pupils identify with the behaviour of teachers because teachers are deemed to be adult models and leaders in creating opinions and attitudes (19-21).

Our research showed that the largest number of subjects $(87 \%)$ were aware of the fact that pupils have the opportunity, during their time in school or in the school yard, to see education workers smoking. In this situation, girls are particularly vulnerable, where a high prevalence of smoking noted amongst the school staff was linked to a greater likelihood of starting to smoke and less likelihood of stopping smoking $(22,23)$.

Since teachers are models and examples for pupils, the importance is stressed of teachers not consuming tobacco and avoiding smoking in the school yard (24). According to data collected by the GYTS (Global Youth Tobacco Survey) research in 
2010, in Italian youth we see that in fact both teachers and pupils often smoke in school and outside of school (44\%), whilst almost $56 \%$ of the subjects stated that they have seen teachers and pupils smoking inside the school building (25). The GYTS data collected in Croatia in 2011 show that as many as $78.7 \%$ pupils are surrounded by people who smoke in closed public spaces (26).

Our research showed that the average age of the subjects who declared themselves to be smokers was 43.61 years, and the average length of time they had been smokers was 14.84 years, which indirectly tells us that education workers start smoking relatively late. Research by various authors shows that most adult smokers lit their first cigarette at an age up to 18 years, or they became dependent before they came of age $(25,27,28)$. Analysis on the group level shows a significant increase in smoking from adolescence to young adulthood, and an insignificant fall after the middle of the second decade of life $(27,29)$.

Due to the risk of developing a state of dependence, preventive programmes should educate young people to take the stance that it is risky to try, and even more to continue to experiment with cigarettes. The results of tests so far suggest that anti-smoking messages sent through schools and the media help to prevent the use of tobacco and the intention to smoke. In contrast, the effects of family warnings of the harmful effects of smoking are, in the best cases, insignificant (30).

Analysis of the results of the Fagestrom test to assess nicotine dependence showed a small number of teachers with severe nicotine dependence. However, a significant number of teachers showed a moderate degree of nicotine dependence, especially when considered in relation to the length of time they had been smoking and the age of the subjects. Women tend to form stronger nicotine dependence than men, although in general they smoke fewer cigarettes a day and have the tendency to use cigarettes with lower nicotine content. Women less often decide to stop smoking and more often relapse after an attempt to stop (31). Our findings indicate that men showed a higher extent of moderate dependence in contrast to women, in whom the predominant dependence was mild.

The effect of teachers who smoke should also be considered in the context of the influence of parents, relatives and friends. The effect increases of the presence of a teacher who smokes in a situation where parents and friends do not smoke (16). The prevalence of smoking in adolescents is significantly lower amongst pupils in countries with moderate to strong national regulations on smoke-free schools in comparison with those in countries with poor implementation or even no school policies in place $(32,33)$. Prohibition of smoking in the public sector may be seen to be successful in reducing smoking in adolescence. In the twenty-first century many countries have signed the Framework Convention of the World Health Organization on Tobacco Control and in recent years an increasing number of countries and regions are implementing partial or complete prohibition of smoking in order to protect the population from passive exposure to smoke (34). Acts on prevention of smoking are deemed to be self-executing. It seems this concept derives from certain developed countries where the cost of implementation is small. It is characteristics that this is seen in jurisdictions with a lower prevalence of smoking and a relatively long history of tobacco control (35).

A review by the International Agency for Research on Cancer of the World Health Organization, taking into account legislative restrictions of smoking of various strengths, has already pointed out that alignment, although it is often satisfactory in most countries, is inadequate in some (35).

Perkins and Neumayer analyse respect for anti-smoking laws in all countries, re- 
gardless of the type of legislation they have, whether comprehensive or limited, complete prohibition of smoking, or only in one or some sectors, or restriction of smoking to certain closed spaces ear-marked for smoking. They found that alignment with the WHO's Framework Convention on Tobacco Control is four times greater in countries with comprehensive national laws, in comparison with countries without strong policies on implementation of legislation on prohibition of smoking (36). So for example, four years after adoption of a comprehensive national law in Greece, the vast majority of its citizens reported smoking in public places. Bosnia and Herzegovina is one of the countries where the rule of law is at a very low level. Further, legislation prohibiting smoking in open spaces could also have other useful effects, such as a reduction in the initiation of young people, the launch of attempts to stop smoking, a reduction in smoking, discussion of and reduction in tobacco consumption in our society, as well as the development of new initiatives dealing with the school environment (37).

The connection between smoking by pupils and smoking by teachers depends on the level of exposure to smoking by teachers. When teachers smoke in schools, this underlines the idea that school anti-tobacco policies are not restrictive and therefore may also reduce the perception of the severity of the penalty linked with violations of policies. It is important to mention that the size of the correlation between teachers smoking and pupils smoking is greater, similar or lower than between parents smoking and children smoking, depending on the level of visibility of the teacher who smokes. Watching a teacher smoke every day, or almost every day, on school grounds, shows a greater correlation with smoking behaviour than in relation to a parent who smokes. The strength of the association is similar when pupils watch a teacher smoke for more than half the day, and lower when the pupils watch the teacher smoke for about half the day (3, 38). Schools provide the ideal environment for preventive initiatives amongst children and adolescents. However, some research has concluded that in the long term there is no consistent effect from prevention programmes in schools (39). Cochrane's review of 2013 considered 49 randomized studies on prevention of smoking amongst schoolaged children and found a significant effect in prevention of pupils starting to smoke amongst pupils who had never smoked. The estimated difference in the incidence of smoking between schools with interventions and controls was $12 \%$ (40).

However, not all programmes were equally effective. Programmes focussing on social competence for instance were more effective than those merely providing information, or focussed solely on social effects. It seems that the success depends on the programme content, the intensity of the intervention and implementation of the programme (41). Intervention for prevention of and stopping smoking that deals with the social context, including life experience, social relationships, organizational structures and social influences have proved to be significant and relevant for the target audience, as well as effective in changing behaviour in health, which may reduce the risk of development of chronic diseases $(42,43)$. The Tobacco-Use Prevention Education (TUPE) programme in California has had significant results. In the schools that finance TUPE, teachers believe that prevention of smoking is a priority, that smoking prevention programmes in their school are effective, and they feel better prepared for prevention of the use of tobacco amongst pupils (44).

\section{Limitations of the Study}

The limitations of this study stem from the fact that it relies on a self-assessment ques- 
tionnaire about something which may be qualified as socially undesirable behaviour. It is important to convince the subjects that their answers are not subject to any form of judgement or disapproval.

In future research it is necessary to test the interest of teachers in participation in programmes to help them stop smoking.

\section{Conclusion}

A quarter of the education workers in $\mathrm{CBC}$ are smokers, and every second smoker has developed a mild level of dependence on nicotine, whilst only an insignificant number of smokers have developed a severe level of dependence. Every fourth subject stated that they respect the prohibition of smoking in school, whilst nine out of ten subjects are aware of the fact that children in school see education workers smoking. In schools in the $\mathrm{CBC}$ there are no preventive programmes to combat smoking by education workers and pupils.

\footnotetext{
What Is Already Known on this Topic

Smoking is not just a bad habit - it is one of the most significant public health problems today. The quality of a smoker's life is much worse and they die earlier. The worrying fact is that the trend of smoking cigarettes among adolescents is increasing. Scientific evidence undoubtedly confirms the harmful effects of tobacco smoke on human health and the quality of life, as well as the fact that there is no safe level of exposure to tobacco smoke. A special form of exposure to tobacco smoke is so-called passive smoking, to which young people and children are particularly exposed due to the irresponsible behaviour of smokers (teachers, parents...).
}

\section{What this Study Adds}

Our survey showed that one in four teachers in schools in the Central Bosnia Canton smoke. An analysis of the results of Fagestrom's nicotine addiction assessment questionnaire identified a significant number of teachers showing a moderate degree of nicotine dependence, especially viewed in relation to the length of time they have been smokers. A significant number of teachers involved in the teaching process, with task of teaching children how to improve their life style habits, are smokers. Students identify with their teachers' behaviour because teachers are considered to be adult role models and leaders in creating opinions and attitudes. The respondents are aware of the fact that while they are in the school or the school yard, students are able to see their teachers smoking.

Authors' Contributions: Conception and design: SK and MP; Acquisition, analysis and interpretation of data: SK, MP, and KE; Drafting the article: SK; Revising the article critically for intellectual content: SK, MP, and KE; Approved final version of the manuscript: SK, and KE.

Conflict of Interest: The authors declare that they have no conflict of interest.

\section{References}

1. Fagerstrom K. A Comparison of Dependence across Different Types of Nicotine Containing Products and Coffee. Int J Environ Res Public Health. 201830;15(8).

2. GBD 2015 Tobacco Collaborators. Smoking prevalence and attributable disease burden in 195 countries and territories, 1990-2015: a systematic analysis from the Global Burden of Disease Study 2015. Lancet. 2017;389(10082):1885-1906.

3. Escario JJ, Wilkinson AV. Visibility of smoking among schoolteachers in Spain and associations with student smoking: a cross-sectional study. BMJ Open. 2018;8: e018736.

4. Roohafza H, Heidari K, Omidi R, Alinia T, Sadeghi M, Mohammad-Shafiee G, et al. Adolescent Perception on School Environment and Smoking Behavior: Analysis of Isfahan Tobacco use Prevention Program. Int J Prev Med. 2014;5(Suppl 2):S139-45.

5. Al-Naggar RA, Jawad AA, Bobryshev YV. Prevalence of cigarette smoking and associated factors among secondary school teachers in Malaysia. Asian Pac J Cancer Prev. 2012;13(11):5539-43.

6. West R. Tobacco smoking: Health impact, prevalence, correlates and interventions. Psychol Health. 2017;32(8):1018-36.

7. West R. The multiple facets of cigarette addiction and what they mean for encouraging and helping smokers to stop. COPD. 2009;6(4):277-83.

8. Fagerstrom KO, Schneider NG. Measuring nicotine dependence: a review of the Fagerstrom Tolerance Questionnaire. J Behav Med. 1989;12(2):15982.

9. Federal Office of Statistics. Central Bosnia Canton in figures: The age structure of the population, assessment on 06/30/2015 [In Bosnian], [cited 2018 Aug 20]. Available from: http://www.fzs.ba/ wp-content/uploads/2019/09/Srednjobosanskikanton-u-brojkama.pdf. 
10. Heatherton TF, Kozlowski LT, Frecker RC, Fagerström KO. The Fagerström Test for Nicotine Dependence: a revision of the Fagerström Tolerance Questionnaire. Br J Addict. 1991;86(9):1119-27.

11. Loring B. Tobacco and inequities. Guidance for addressing inequities in tobacco-related harm. Copenhagen, Denmark: WHO Regional Office for Europe; 2014. p. 5-6.

12. Tobaccoatlas.org Prevalence. [cited 2019 Feb 10] Available from: http://www.tobaccoatlas.org/ topic/prevalence.

13. Giovino GA, Mirza SA, Samet JM, Gupta PC, Jarvis MJ, Bhala N, et al. Tobacco use in 3 billion individuals from 16 countries: an analysis of nationally representative cross-sectional household surveys. Lancet. 2012;380(9842):668-79.

14. WHO. Global health risks: mortality and burden of disease attributable to selected major risks. [cited 2019 Feb 12] Available from: http://www. who.int/healthinfo/global burden disease/GlobalHealthRisks.

15. Fidler JA, West R, van Jaarsveld CH, Jarvis MJ, Wardle J. Smoking status of step-parents as a risk factor for smoking in adolescence. Addiction. 2008;103(3):496-501.

16. Fidler JA, West R, Jarvis MJ, Wardle J. Early dating predicts smoking during adolescence: A prospective study. Addiction. 2006;101(12):1805-13.

17. Poulsen LH, Osler M, Roberts C, Due P, Damsgaard MT, Holstein BE. Exposure to teachers smoking and adolescent smoking behaviour: analysis of cross sectional data from Denmark. Tob Control. 2002;11(3):246-51.

18. Huang HW, Lu CC, Yang YH, Huang CL. Smoking behaviours of adolescents, influenced by smoking of teachers, family and friends. Int Nurs Rev. 2014;61(2):220-7.

19. Piontek D, Buehler A, Rudolph U, Metz K, Kroeger C, Gradl S, et al. Social contexts in adolescent smoking: does school policy matter? Health Educ Res. 2008;23(6):1029-38.

20. Stokols D. Establishing and maintaining healthy environments. Toward a social ecology of health promotion. Am Psychol. 1992;47(1):6-22.

21. Bandura A. Social learning theory. Englewood Cliffs, NJ: Prentice Hall; 1977.

22. Barnett TA, Gauvin L, Lambert M, O'Loughlin J, Paradis G, McGrath JJ. The influence of school smoking policies on student tobacco use. Arch Pediatr Adolesc Med. 2007;161(9):842-8.

23. Virtanen $M$, Pietikäinen $M$, Kivimäki M, Luopa P, Jokela J, Elovainio M, et al. Contribution of parental and school personnel smoking to health risk behaviours among Finnish adolescents. BMC Public Health. 2009;9:382.

24. Sinha DN, Gupta PC, Dobe M, Prasad VM. Tobacco control in schools of India: review from India Global School Personnel Survey 2006. Indian J Public Health. 2007;51(2):101-6.

25. Charrier L, Berchialla P, Galeone D, Spizzichino L, Borraccino A, Lemma P, et al. Smoking habits among italian adolescents: what has changed in the last decade? Biomed Res Int. 2014;2014:287139.

26. Hibell B, Guttormsson U, Ahlström S, Balakireva O, Bjarnason T, Kokkevi A,et al. The 2011 ESPAD Report. Substance use among students in $36 \mathrm{Eu}-$ ropean countries. Sweden, Stockholm: The Swedish Council for Information on Alcohol and other Drugs (CAN); 2012.

27. Chassin L, Presson CC, Rose JS, Sherman SJ. The natural history of cigarette smoking from adolescence to adulthood: demographic predictors of continuity and change. Health Psychol. 1996;15(6):478-84.

28. Jarvis MJ. Why people smoke. BMJ. 2004;328 (7434):277-9.

29. Jarvis MJ, Feyerabend C. Recent trends in children's exposure to second-hand smoke in England: cotinine evidence from the Health Survey for England. Addiction. 2015;110(9):1484-92.

30. Yu S, Koplan J, Eriksen MP, Yao S, Redmon P, Song J, et al. The Effects of Antismoking Messages From Family, School, and Mass Media on Smoking Behavior and Smoking Intention Among Chinese Adolescents. J Health Commun. 2015;20(11):1255-63.

31. Allen AM, Oncken C, Hatsukami D. Women and Smoking: The Effect of Gender on the Epidemiology, Health Effects, and Cessation of Smoking. Curr Addict Rep. 2014;1(1):53-60.

32. Agaku IT, Obadan EM, Odukoya OO, Olufajo O. Tobacco-free schools as a core component of youth tobacco prevention programs: a secondary analysis of data from 43 countries. Eur J Public Health. 2015;25(2):210-5.

33. Wold B, Torsheim T, Currie C, Roberts C. National and school policies on restrictions of teacher smoking: a multilevel analysis of student exposure to teacher smoking in seven European countries. Health Educ Res. 2004;19(3):217-26.

34. Kelleher CC, Frazer K. An international smoking ban-how many lives will be saved? Curr Atheroscler Rep. 2014;16(6):418.

35. Peruga A, Hayes LS, Aguilera X, Prasad V, Bettcher DW. Correlates of compliance with national comprehensive smoke-free laws. Tob Control. 2018;27:608-13. 
36. Perkins R, Neumayer E. Adoption and compliance in second-hand smoking bans: a global econometric analysis. Int J Public Health. 2014;59(5):85966.

37. Thomson G, Wilson N, Edwards R. At the frontier of tobacco control: a brief review of public attitudes toward smoke-free outdoor places. Nicotine Tob Res. 2009;11(6):584-90.

38. Noland M, Rayens MK, Riggs RS, Staten R, Hahn E, Riker C. Student and principal perceptions of school tobacco policy. Am J Health Educ. 2011;42(1):41-9.

39. de Kleijn MJ, Farmer MM, Booth M, Motala A, Smith A, Sherman S, et al. Systematic review of school-based interventions to prevent smoking for girls. Syst Rev. 2015;4:109.

40. Thomas RE, McLellan J, Perera R. School-based programmes for preventing smoking. Cochrane Database Syst Rev. 2013;(4):CD001293.
41. Thomas RE, McLellan J, Perera R. Effectiveness of school-based smoking prevention curricula: systematic review and meta-analysis. BMJ Open. 2015;5(3):e006976.

42. Sorensen G, Emmons K, Hunt MK, Barbeau E, Goldman R, Peterson K, et al. Model for incorporating social context in health behavior interventions: applications for cancer prevention for working-class, multiethnic populations. Prev Med. 2003;37(3):188-97.

43. Sorensen G, Barbeau E, Hunt MK, Emmons K. Reducing social disparities in tobacco use: a social-contextual model for reducing tobacco use among blue-collar workers. Am J Public Health. 2004;94(2):230-9.

44. McMenamin SB, Cummins SE, Zhuang YL, Gamst AC, Ruiz CG, Mayoral A, et al. Evaluation of the Tobacco-Use Prevention Education (TUPE) program in California. PLoS One. 2018;13(11):e0206921. 